\title{
Drug use questions in Norwegian health surveys - response rate and agreement between specific and open-ended questions
}

\author{
Kari Furu ${ }^{1,2}$, Svetlana Skurtveit ${ }^{1}$ and Elin O. Rosvold ${ }^{2}$ \\ ${ }^{1}$ Division of Epidemiology, Norwegian Institute of Public Health, Oslo \\ ${ }^{2}$ Institute of General Practice and Community Medicine, University of Oslo \\ Correspondence: Kari Furu, Division of Epidemiology, Norwegian Institute of Public Health, P.O. Box 4404 Nydalen, N-0403 Oslo, Norway \\ Telephone: +4723408185 e-mail: kari.furu@fhi.no
}

\begin{abstract}
Self-reported use of drugs obtained through a questionnaire as a part of health surveys is commonly used as a source of drug exposure information. In the present study we have introduced a questionnaire that includes details such as frequency of use, trade names, and reason for using the drugs. The aim of the study was to estimate the item response rate to drug use questions, and to assess the agreement between questions on use of drug categories (cholesterol-lowering drugs, hypnotics, and antiepileptics) and openended questions on trade names in two Norwegian health surveys. The urban population in the Oslo Health Study included all individuals living in Oslo born in 1970, 1960, 1955, 1940/41, and 1924/25. A total of 40,888 citizens were invited, 8,404 (42\%) men and 10,366 (49\%) women attended a physical examination and/or filled in at least one questionnaire. The design of the Oppland/Hedmark Health Study was similar to the Oslo Health Study. Among this rural population 22,272 citizens were invited, 5,684 $(52 \%)$ men and 6,820 (61\%) women participated. There was a high item response rate on the questions on drug categories in both health surveys, ranging from $80.6 \%$ to $99.8 \%$ among those who attended the surveys. Report on trade names was higher for cholesterol-lowering drugs than for hypnotics in both men and women. Report on trade names was higher in the rural population than in the urban population. There was a high concordance between trade names of antiepileptics written in the main questionnaire, and the trade names that were ticked off later on in the supplementary questionnaire (only in the Oppland County). These standardised drug use questions will make the comparability between the Norwegian health surveys easier and facilitate the ability to combine results from several studies in the future.
\end{abstract}

\section{INTRODUCTION}

Self-reported use of drugs obtained through a questionnaire as a part of health surveys is commonly used as a source of drug exposure information (1-7). Health surveys have the advantage of collecting information on both prescription and non-prescription drugs, as well as information on health status, health risk factors, and sociodemographic variables. As Norway has only gross-volume drug sales data and so far no individually based drug prescription registers, we have to rely on self-reported drug use in health surveys in order to get information on an individual basis. Individual information about this use in Norway has been collected through a series of health surveys, many of which have been undertaken as a part of cardiovascular preventive programs by The National Health Screening Service (now The Norwegian Institute of Public Health) $(1,8)$. Until recently, the majority of the Norwegian health surveys have included rather simple dichotomous questions on drug use (9).

Construction and preparation of questionnaires are essential for the quality of data, but epidemiologists have paid too little attention to the quality of the raw data in epidemiologic research $(10,11)$. Questionnaire development and validation of drug use questions other than hormones or pregnancy related exposures have been scarce (12). Furu and Thelle have shown that using "yes" or "no" as the only outcome of drug questions has the unfortunate effect of putting together chronic users of drugs with infrequent users, which may result in a considerable measurement error (13). This implies that it is crucial to include more details in questions on drug use, such as the frequency and duration of use. When preparing and planning for the Oslo Health Study (HUBRO) more attention was therefore given to include drug use questions with a more focused approach. These questions were replicated in the corresponding study in Oppland and Hedmark (OPPHED).

The objectives of the present analysis are to:

- assess the response rate to questions on drug use in an urban and a rural population in Norway.

- estimate the agreement between questions on drug categories and open-ended questions on drug trade names in an urban and a rural population in Norway. 


\section{MATERIAL AND METHODS}

\section{Oslo Health Study (2000-2001)}

In 2000-2001 the Oslo Health Study was conducted under the joint collaboration of the National Health Screening Service of Norway (now the Norwegian Institute of Public Health), the University of Oslo, and the Municipality of Oslo. All individuals in Oslo County born in 1970, 1960, 1955, 1940/41 and 1924/25 were invited to attend a health screening. In this urban population a total of 40,888 citizens were invited, 8,404 men $(42.4 \%)$ and 10,366 women $(49.3 \%)$ attended a physical examination and/or filled in at least one questionnaire. For the five age cohorts the participation rates were $36,44,47,55$ and $53 \%$, respectively.

Baseline measurements at the physical examination included height, weight, waist and hip circumference, blood pressure, heart rate, and non-fasting blood tests to analyse serum total cholesterol, HDL-cholesterol, triglycerides, and glucose. One self-administered questionnaire (the main questionnaire) was part of the letter of invitation, and was to be filled in at home and handed in on arrival to the health screening. Two supplementary questionnaires were handed out at the screening, filled in at home and returned in pre-stamped self-addressed envelope. The questionnaires provided information on various aspects of health, for example health status, symptoms, diseases, and a set of different questions on drug use.

Up to two reminders were sent to those who did not attend the health screening. In the second reminder suburban citizens were invited to mobile screening units parked in their neighbourhood. Those unable to attend the screening in person in these suburban parts were requested to return the main questionnaire by mail. In this second letter of reminding we offered immigrants with poor Norwegian language skills, assistance from field-workers to complete the questionnaires. Attendees who did not return the supplementary questionnaires were reminded once within three to twelve months after the screening.

The study protocol was assessed by the Regional Committee for Medical Research Ethics and approved by the Norwegian Data Inspectorate. The study has been conducted in full accordance with the World Medical Association Declaration of Helsinki.

\section{Drug use questions}

Figure 1 displays the drug use questions used in the Oslo Health Study. The set of questions was developed by two of the authors (KF and EOR) based on the existing knowledge from different health surveys in Norway and was part of the main questionnaire (9). The questions in Figure 1 are divided in four parts. Use of antihypertensives and cholesterol-lowering drugs (part 1) were asked for in the same way as in previous studies conducted by the National Health Screening Service (9). The new study design is given in parts 2 and 3. It consists of the combination of a specific question on the frequency of use of different drug categories during the last four weeks (part 2), followed by an open question on drug trade names, reason for taking the drugs, and duration of treatment (part 3). These questions in part 3 also captured corresponding trade names to the questions about anti-

\section{USE OF MEDICINES}

Medicines, in this context, means medicines bought at a pharmacy. Food supplements and vitamins are not included her. Part 1

$\begin{array}{lcll}\text { 13.1 Do you take? } & \text { Now } & \begin{array}{l}\text { Earlier, } \\ \text { but not } \\ \text { now }\end{array} & \begin{array}{l}\text { Never } \\ \text { used }\end{array} \\ \text { Antihypertensives........................ } & \square & \square & \square \\ \text { Cholesterol-lowering drug............... } & \square & \square & \square\end{array}$

Part 2

13.2 How often during the last 4 weeks have you taken the following medicines?

(One cross per line) Daily Every Less often Not taken week but than during the
not daily every week last 4 weeks

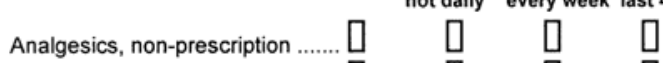
Analgesics, on prescription .......... $\square \square \square \square$

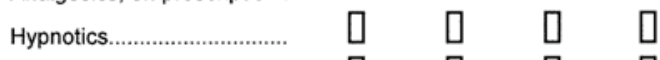
Tranquillisers................ $\square \square \square \square$

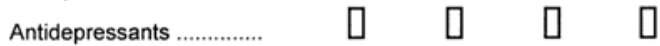
Other medicines on prescription... $\square_{1} \quad \square_{2} \quad \underset{3}{\square} \square_{4}$

Part 3

13.3 For those medicines you have ticked off in 13.1 and 13.2 , and taken during the last 4 weeks :

State the name of the medicines and your reason for taking them (disease, symptom):

(Tick off for how long you have taken the medicines)

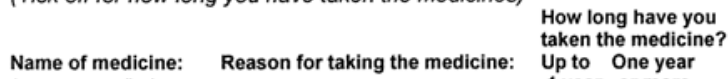
(one name per line): $\quad$ Reason for taking the medicine: Up to One year $\longrightarrow \square \square$

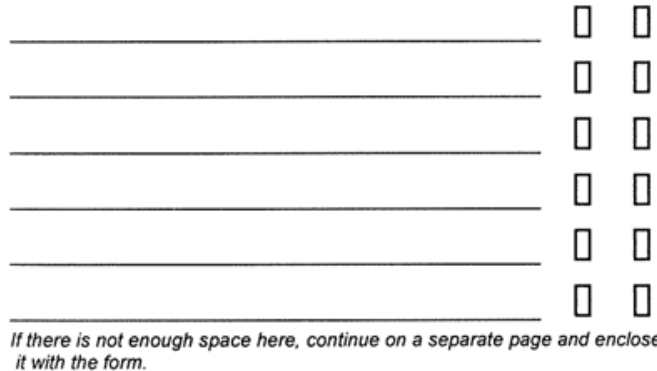

If there is not enough space here, continue on a separate page and enclose it with the form.

\section{Part 4}

14.5 Do you use or have you used? (One cross on each line)

P-pill / minipill/p-injection .........
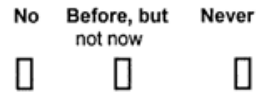

Hormone loop. $\begin{array}{lll}0 & 0\end{array}$

Oestrogen (tablets or plaster)

Oestrogen (cream or suppositories)

14.6. If you take /have taken oestrogen that is on prescription: How long have you taken this ? ................. Number yrs

14.7 If you use the p-pill, mini-pill, p-injection, Hormone loop or oestrogen; which preparation do you use?

Figure 1. Questions on use of medicines as part of the main questionnaire in the Oslo Health Study 2000-2001 (HUBRO) and the Oppland and Hedmark study 2000-2001 (OPPHED). 
hypertensives and cholesterol-lowering drugs in part one, and the question about "other medicines on prescription" in part two.

Included in the main questionnaire were also questions on use of contraceptives and estrogens (part 4 in Figure 1). These questions are not analysed in the present paper. The oldest age group (born 1924 and 1925) received a modified version of the questionnaire (14). Part 1 in this questionnaire included supplementary questions on insulin and medicine for osteoporosis and diabetes, and part 2 included only one question on analgesics, not divided between non-prescription and prescription analgesics. Part 4 included only questions on hormone replacement treatment (9).

The Access ${ }^{\mathrm{TM}}$ database was used to register trade name on drugs and the diagnosis from the open questions in the main questionnaire. The whole ATC (Anatomic Therapeutic Chemical classification) code system Version 2000 was placed in the database together with the International Classification of Primary care (ICPC) $(15,16)$. It was possible to register up to ten different trade names and the corresponding diagnosis. Only $0.1 \%$ of attendees in the two surveys reported ten different trade names.

\section{Oppland and Hedmark Health Study (2000-2001)}

In 2000-2001 Norwegian Institute of Public Health performed a health survey in the rural counties of Oppland and Hedmark (OPPHED). The study population and procedures were similar to the Oslo Health Study. Among the 22,272 citizens invited, 5,684 (52\%) men and 6,820 (61\%) women participated. The main questionnaire from the Oslo Health Study was used in this study, and it thus contained the same questions on drug use as described above (Figure 1). The supplementary questionnaires in Oppland and Hedmark differed from the questionnaires used in the Oslo Health Study (17). Some of the questionnaires were handed out to all attendees, while other supplementary questionnaires were applied only to selected groups. One of the supplementary projects investigated the prevalence of epileptic disorders among adults in the county of Oppland, solely (17). The main objective was to explore the use of drugs in different groups of epilepsy patients. The questions on antiepileptic drugs are shown in Figure 2. The supplementary questionnaire was handed out at the screening, filled in at home and returned later in a pre-stamped self-addressed envelope. Among those attending the screening in Oppland, the response rate to the supplementary questionnaire on epilepsy was $77 \%(2,117)$ in men and $82 \%(2,755)$ in women.

More detailed information concerning participation in HUBRO can be obtained from a study by Søgaard et al., and at the homepage of The Norwegian Institute of Public Health $(14,18)$.

Data were analysed using SPSS for Windows (version 10) (19).

\section{EPILEPSY}

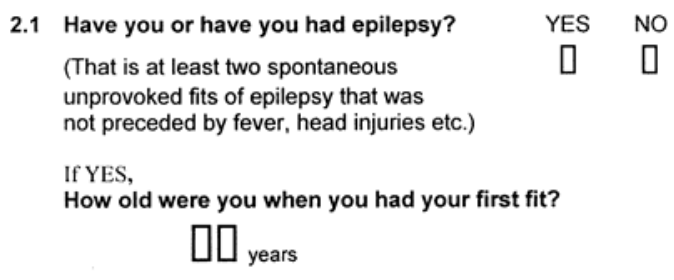

2.2 Do you use medicines for your epilepsy now? YES NO

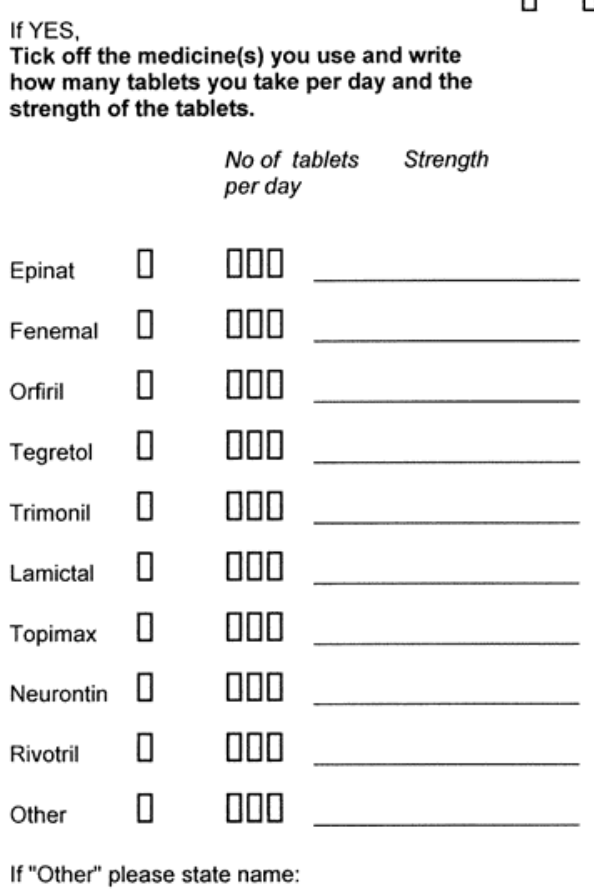

Figure 2. Questions on use of antiepileptics as part of the supplementary questionnaire in the Oppland County (OPPHED). Trade name of antiepileptics represents the following ATC coding: Epinat N03A B02, Fenemal N03A A02, Orfiril N03A G01, Tegretol/Trimonil N03A F01, Lamictal N03A X09, Topimax N03A X11, Neurontin N03A X12, Rivotril N03A E01.

\section{ReSUlts}

\section{Response rate on questions on different drug categories}

Table 1 shows the response rate on the different questions on use of drugs for men and women who attended the screenings in Oslo and Oppland/Hedmark. The item response rate ranged from $80.6 \%$ on antidepressants among 75 years old women in OPPHED to $99.8 \%$ on antihypertensives and cholesterol-lowering drugs among 30 years old women in OPPHED. More than $94 \%$ of the youngest participants answered the drug use questions, whilst older attendees had a low response rate especially on psychotropic drugs. The higher item response rate among young participants was found in both genders, and this trend was observed in both HUBRO and OPPHED. 
Table 1. Item response rate (\%) of attendees on question on use of different categories of drugs according to gender and age. Oslo Health Study 2000-2001 (HUBRO) and Oppland and Hedmark Health Study 2000-2001 (OPPHED).

\begin{tabular}{|c|c|c|c|c|c|c|c|c|}
\hline \multirow{2}{*}{$\begin{array}{l}\text { HUBRO } \\
\text { Age, years }\end{array}$} & \multicolumn{4}{|c|}{ Men } & \multicolumn{4}{|c|}{ Women } \\
\hline & 30 & $40+45$ & 60 & 75 & 30 & $40+45$ & 60 & 75 \\
\hline $\begin{array}{l}\text { Number of attendees, } \mathrm{N} \\
\text { Part } 1\end{array}$ & 1826 & 2936 & 2117 & 1525 & 2288 & 3662 & 2357 & 2059 \\
\hline Antihypertensives, $\%$ & 99.0 & 98.7 & 97.7 & 96.8 & 99.1 & 98.8 & 97.6 & 96.4 \\
\hline $\begin{array}{l}\text { Cholesterol-lowering drug, \% } \\
\quad \text { Part } 2\end{array}$ & 98.9 & 98.3 & 96.9 & 94.7 & 98.6 & 98.3 & 96.4 & 91.9 \\
\hline Analgesics, non-prescription, $\%$ & 98.9 & 94.4 & 89.9 & \multirow{2}{*}{$90.4^{*}$} & 96.8 & 95.8 & 90.1 & \multirow{2}{*}{$89.3^{*}$} \\
\hline Analgesics, on prescription, $\%$ & 97.0 & 93.4 & 89.7 & & 95.1 & 93.1 & 87.3 & \\
\hline Hypnotics, \% & 95.8 & 92.1 & 88.9 & 88.9 & 95.1 & 91.9 & 84.4 & 88.0 \\
\hline Tranquillisers, \% & 95.4 & 92.0 & 87.9 & 88.3 & 94.4 & 91.0 & 83.4 & 83.1 \\
\hline Antidepressants, $\%$ & 95.4 & 92.2 & 87.5 & 87.2 & 94.3 & 91.5 & 82.1 & 81.3 \\
\hline Other medicine on prescription, $\%$ & 95.5 & 93.3 & 92.2 & 90.2 & 94.7 & 92.7 & 88.5 & 87.7 \\
\hline \multicolumn{9}{|l|}{ OPPHED } \\
\hline Age, years & 30 & $40+45$ & 60 & 75 & 30 & $40+45$ & 60 & 75 \\
\hline $\begin{array}{l}\text { Number of attendees, } \mathrm{N} \\
\text { Part } 1\end{array}$ & 791 & 2724 & 1271 & 898 & 1115 & 3299 & 1418 & 988 \\
\hline Antihypertensives, $\%$ & 99.6 & 99.5 & 97.6 & 97.4 & 99.8 & 99.5 & 98.0 & 96.8 \\
\hline $\begin{array}{l}\text { Cholesterol-lowering drug, \% } \\
\quad \text { Part } 2\end{array}$ & 99.5 & 99.3 & 95.9 & 94.4 & 99.8 & 99.0 & 95.8 & 91.6 \\
\hline Analgesics, non-prescription, $\%$ & 97.5 & 96.4 & 89.0 & \multirow{2}{*}{$90.8^{*}$} & 98.4 & 96.9 & 89.3 & \multirow{2}{*}{$87.0^{*}$} \\
\hline Analgesics, on prescription, $\%$ & 96.6 & 95.9 & 88.8 & & 96.9 & 94.7 & 89.3 & \\
\hline Hypnotics, \% & 95.4 & 94.6 & 86.7 & 87.9 & 95.6 & 92.6 & 82.8 & 85.5 \\
\hline Tranquillisers, $\%$ & 95.3 & 94.3 & 86.1 & 86.7 & 95.4 & 92.1 & 81.3 & 82.2 \\
\hline Antidepressants, \% & 95.3 & 94.6 & 85.5 & 85.7 & 95.7 & 92.5 & 80.7 & 80.6 \\
\hline Other medicine on prescription, $\%$ & 96.2 & 95.4 & 90.2 & 90.3 & 96.4 & 93.9 & 88.3 & 90.3 \\
\hline
\end{tabular}

* The question addressed to persons aged 75 years were not divided on non-prescription and prescription analgesics.

\section{Agreement between questions on drug categories and open-ended questions on trade names}

The questionnaire data on the drug categories (part 1 and part 2 in Figure 1) were compared with data from the open question on trade names (part 3 in Figure 1). Two categories of drugs have been studied in more detail: cholesterol-lowering drugs (ATC-code C10) and hypnotics (ATC-code N05B).

In the Oslo population, $71.7 \%$ of those who reported present use of cholesterol-lowering drugs in part 1 of the questionnaire, gave the trade name in part 3 in Figure 1. The corresponding figure in OPPHED was $80.5 \%$. Table 2 shows the gender-specific reporting of trade names of cholesterol-lowering drugs in HUBRO and OPPHED. Report was higher for present users compared to previous users of cholesterol-lowering drugs both among males and females in HUBRO. The same results were found in OPPHED.

For hypnotics (Table 3) the report of trade names was lower than for cholesterol-lowering drugs. In both populations of Oslo and Oppland/Hedmark, daily and every week users of hypnotics were more likely to report trade names than those who used the drugs less often. This was found for both males and females.

The report of trade names among present users of drugs was higher in the rural population of OPPHED than in urban HUBRO both on cholesterol-lowering drugs and on hypnotics. Women reported more often than men trade names for both cholesterol-lowering drugs and hypnotics. Attendees aged 30 years had the lowest report of trade names of cholesterol-lowering drugs, only $25 \%$ of and $28 \%$ of present users, men and women, respectively. Similar results were found for daily users of hypnotics aged 30 years. Only $10 \%$ of male and $38 \%$ of female users reported hypnotic trade names.

\section{Antiepileptics: agreement between main and supple- mentary questionnaire in Oppland County}

The answers on use of antiepileptics from the supplementary questionnaire in Oppland (figure 2) were compared with the main questionnaire in the health survey in this county (figure 1). In all, 75 persons reported current or previous epilepsy in the supplementary questionnaire. Among these, 39 subjects reported current use of at least one antiepileptic drug (question 2.2 in figure 2). Table 4 shows the number and frequencies of the trade names ticked off in the supplementary questionnaire by the 39 subjects. Six subjects used two different antiepileptics and one person ticked off three different trade names. In the main questionnaire, the attendees reported 42 corresponding trade names (part 3 in figure 1) of the 47 trade names (89\%) ticked off later on in the supplementary questionnaire (figure 2). Thirty-eight of the 42 trade names $(90 \%)$ were reported together with a diagnosis of epilepsy in the main questionnaire. 
Table 2. Report of trade names among responders to question on use of cholesterol-lowering drugs, by type of response and gender. Oslo Health Study 2000-2001 and Oppland /Hedmark Health Study 2000-2001.

\begin{tabular}{lllrc}
\hline & & \multicolumn{2}{l}{ Question: "Do you take cholesterol-lowering drugs?" } \\
\cline { 3 - 5 } & & Type of response & $\begin{array}{c}\text { Number } \\
\text { respon- } \\
\text { ding }\end{array}$ & $\begin{array}{c}\text { Number (per cent) } \\
\text { reporting trade } \\
\text { names* }\end{array}$ \\
\hline Oslo & \multirow{2}{*}{ Men } & Now & 722 & $504(69.8)$ \\
& & Earlier, but not now & 97 & $6(6.2)$ \\
& & Never & 7353 & $6(0.1)$ \\
& \multirow{2}{*}{ Women } & Now & 637 & $471(73.9)$ \\
& & Earlier, but not now & 75 & $5(6.7)$ \\
Oppland & \multirow{2}{*}{ Men } & Never & 9308 & $3(0.0)$ \\
Hedmark & & Now & 528 & $417(79.0)$ \\
& & Earlier, but not now & 78 & $4(5.1)$ \\
& & Never & 4954 & $4(0.1)$ \\
& \multirow{2}{*}{ Women } & Now & 483 & $397(82.2)$ \\
& & Earlier, but not now & 40 & $4(10.0)$ \\
& & Never & 6169 & $2(0.0)$ \\
\hline
\end{tabular}

* ATC-code: C10AA01-06

Table 3. Report of trade names among respondents to question on use of hypnotics by type of response and gender. Oslo Health Study 2000-2001 and Oppland /Hedmark Health Study 2000-2001.

\begin{tabular}{|c|c|c|c|c|}
\hline & & \multicolumn{3}{|c|}{$\begin{array}{c}\text { Question "How often during the last } 4 \text { weeks have you } \\
\text { taken hypnotics?" }\end{array}$} \\
\hline & & Type of response & $\begin{array}{l}\text { Number } \\
\text { respon- } \\
\text { ding }\end{array}$ & $\begin{array}{l}\text { Number (per } \\
\text { cent) reporting } \\
\text { trade names* }\end{array}$ \\
\hline \multirow[t]{8}{*}{ Oslo } & Men & Daily & 193 & $78(40.4)$ \\
\hline & & Every week but not daily & 190 & $83(43.7)$ \\
\hline & & Less often than every week & 231 & $57(24.7)$ \\
\hline & & Not taken the last four weeks & 7069 & $5(0.1)$ \\
\hline & Women & Daily & 430 & $205(47.7)$ \\
\hline & & Every week but not daily & 406 & $170(41.9)$ \\
\hline & & Less often than every week & 482 & $125(25.9)$ \\
\hline & & Not taken the last four weeks & 8007 & $5(0.1)$ \\
\hline \multirow{8}{*}{$\begin{array}{l}\text { Oppland } \\
\text { and } \\
\text { Hedmark }\end{array}$} & Men & Daily & 118 & $57(48.3)$ \\
\hline & & Every week but not daily & 67 & $29(43.3)$ \\
\hline & & Less often than every week & 104 & $18(17.3)$ \\
\hline & & Not taken the last four weeks & 4935 & $1(0.0)$ \\
\hline & Women & Daily & 258 & $135(52.3)$ \\
\hline & & Every week but not daily & 194 & $107(55.2)$ \\
\hline & & Less often than every week & 234 & $65(27.8)$ \\
\hline & & Not taken the last four weeks & 5454 & $6(0.1)$ \\
\hline
\end{tabular}

* ATC-code: N05CD02, N05CD03, N05CD08, N05CF01, N05CF02 and N05CM02

\section{DisCUSSION}

There was a high item response rate on the questions on drug categories in the two health surveys, ranging from $80.6 \%$ to $99.8 \%$ among those who attended the surveys, depending on age and drug categories. Knowledge of trade names was higher for cholesterollowering drugs compared to hypnotics for both men and women, and higher in the rural population than in the urban population. Women reported trade names more often than men. In Oppland, there was a high concordance $(89.4 \%)$ between trade names of antiepileptics written in the main questionnaire, and the trade names that were ticked off later on in the supplementary questionnaire.

One important potential selection bias in the present health studies is the non-response; either nonattendance to the screening or non-response to the different items in the questionnaires. The consequences of non-attendance in the Oslo Health Study are analysed, by linking sociodemographic information from Statistics Norway to data from the physical examination and the questionnaires (18). The typical nonattendees in the Oslo Health Study were young unmarried males, belonging to the lower income and educational echelons, and living in the urban sectors of the city. The conclusion of the study was however, that the prevalence estimates are robust even in light of considerable non-attendance. The rural survey from Oppland/Hedmark had a higher attendance rate, but a corresponding analysis has not been performed on data from this area.

An increasing problem for all surveys is the growing danger of survey fatigue, which has a negative impact on attendance rates. However, the completeness of data at an item level among the attendees is also of great importance. Our study shows that the item response rates to the questions on cholesterol lowering drugs and antihypertensives were nearly $100 \%$. However, for the psychotropic drug categories, such as antidepressants, the item response rates were lower, about $80 \%$ in older women. Some of those who did not answer may have considered the questions as irrelevant because they were non-users. Others may have considered some questions sensitive, such as the psychotropic drugs, and therefore not answered these questions.

Large differences in knowledge of trade names were observed between the different drug categories. For hypnotics the report of trade names was lower than for cholesterol-lowering drugs. Regular users (daily or weekly) of hypnotics reported trade names twice as often as those who used these drugs less than weekly. These findings are in accordance with results from other studies that show an accurate recall of medical and drug usage history in well-defined chronic conditions $(20,21)$. In a study from Canada reporting trade names on antihypertensives was $71 \%$, and for tranquilizers/sedatives $26 \%$, for those who had reported these drug categories in a self-reporting questionnaire (22). The stigmata of mental illness may result in underreporting of psychotropics. The low report of trade names among young users can also indicate that this age group finds the use of such drugs more stigmatising than older groups.

Patients with epileptic disorders reported their use of antiepileptics by ticking off yes or no on a list of trade names in the supplementary questionnaire. When these answers were compared to the trade names that 
Table 4. Agreement between reporting antiepileptics on main and supplementary questionnaire in Oppland county (part of the Oppland and Hedmark Health Study 2000-2001).

\begin{tabular}{lccc}
\hline Trade names of antiepileptics & $\begin{array}{c}\text { Number of attendees } \\
\text { who ticked off use of } \\
\text { drug in supplementary } \\
\text { questionnaire }\end{array}$ & $\begin{array}{c}\text { Number of attendees who } \\
\text { stated equal trade name of } \\
\text { drug in open question in } \\
\text { the main questionnaire (\%) }\end{array}$ & $\begin{array}{c}\text { Number who stated epilepsy } \\
\text { disorder when reporting use of } \\
\text { antiepileptic in open question } \\
\text { in the main questionnaire (\%) }\end{array}$ \\
\hline Epinat (N03AB02) & 3 & $2(67)$ & $2(67)$ \\
Fenemal ((N03AA02) & 2 & $2(100)$ & $2(100)$ \\
Orfiril (N03AG01) & 10 & $8(80)$ & $8(80)$ \\
Tegretol (N03AF01) & 21 & $20(95)$ & $16(76)$ \\
Trimonil (N03AF01) & 3 & $3(100)$ & $3(100)$ \\
Lamictal (N03AX09) & 5 & $5(100)$ & $5(100)$ \\
Topimax (N03AX11) & 2 & $1(50)$ & $1(50)$ \\
Neurontin (N03AX12) & 1 & $1(100)$ & $1(100)$ \\
Rivotril (N03AE01) & 0 & - & - \\
\hline
\end{tabular}

the attendees wrote by themselves in the main questionnaire, high agreement was found in spite of a time delay between the two different questionnaires and different design of the questions. This might be because epilepsy belongs to the group of well-defined chronic conditions that often give accurate recall of the drug usage history $(20,21)$. In the main questionnaire ninety percent of the current users of antiepileptics reported also an epilepsy disorder. This may imply that people understand what kind of disorder they are using the drugs for.

The report of trade names among present users of drugs was higher in the rural than in the urban population both on cholesterol-lowering drugs and hypnotics. The population in the capital city Oslo is multiethnic, and language difficulties may thus explain lower reporting. The questionnaires were filled in at home, which makes it possible to check the drug trade names in the medicine cabinet. Rural populations may be inclined to spend more time to answer the questions and thereby more precisely, while the urban and the young populations are busier and do not want to spend time. This may correspond to the phenomena that the attendance at health surveys is higher in rural areas than in more urban regions $(14,17)$. Attendees aged 30 years had the lowest report of trade names, and they also had the lowest attendance rate in these two health surveys $(14,17)$. Women reported trade names more often than men both for cholesterol-lowering drugs and hypnotics.

A review of the validity of drug exposure data from questionnaires has shown that using different types of drug questions provide more complete drug data (12). In HUBRO and OPPHED we have expanded the drug use questions from previous health surveys by combining indication-specific questions with open-ended questions asking for more details, such as frequency of use, trade names, and reason for using the drugs. Different recall periods were used depending on drug category. For chronic conditions such as high blood pressure and hypercholesterolemia, drug use was re- corded as point prevalence ("now"). Other drug groups that were used both regularly and sporadic, e.g. analgesics and psychotropics, were recorded by a recall period of four weeks together with the frequency of use. Increasing the recall period from two weeks to four weeks increases the risk for underreporting, while a disadvantage of using shorter time periods is the underrepresentation of occasional users of drugs. Our results show that more than $30 \%$ of hypnotic users used these drugs less than every week, and some of these sporadic users will be missed if recall period were shorter. The high response rate on drug categories where frequency of use were registered by a recall period of four weeks, indicate that most of the attendees found the answering categories suitable for their pattern of use. The high completeness of data at this item level shows also a high willingness to participate and to provide the wanted information on drug use. This is important, because a questionnaire should not only provide valid responses, but also be well accepted by the responders.

As the length of time between taking the drug and answering the questionnaire increases, the patient's ability to recall declines. Responders who use hypnotics less often than every week reported trade names more seldom than regular users. Information about frequency and duration of drug use will give us a more accurate measurement of the drug exposure, which may reduce misclassification (13). With the possibility of knowing the exact trade names of different categories of drugs, future follow-up studies will be able to examine differences between substances in the same therapeutic group. The limited number of registered drugs in Norway compared to other European countries makes it more likely that the public is familiar with the drug names and their appropriate use, increasing the validity of self-report of drug usage in Norway.

The question "Other medicines on prescription" as a part of the questions about drug categories is included to capture other than listed drug categories, such 
as antiepileptics. The agreement on trade names on antiepileptics between the open question on trade names in the main questionnaire and stated trade names in the supplementary questionnaire shows that this question functions as intended.

Epidemiologists have to rely upon self-reported data with the inherent problems of inaccurate reporting. Great effort should be undertaken to reduce this as much as possible (23). However, West et al. are concluding that the longstanding and widespread concern about substantial recall bias as a major concern in studies of medication use appears to be a misapprehension (12). Furthermore the recent literature suggests that the type of medication, drug use patterns, the design of the data collection materials, and respondent characteristics sometimes influence recall accuracy of self-reported medication exposures (12). In the Oslo Health Study we have expanded the drug use questions by including more details, such as frequency of use, trade names and reason for using the drugs. The same study design, handling and ascertainment of the drug use questions as in the Oslo Health Study have later been used in the successive population surveys performed by the Norwegian Institute of Public Health. This includes the health studies in the counties of Oppland and Hedmark (OPPHED), Troms and Finnmark (TROFINN), the Tromsø V Health Survey, the health examination at Romsås and Furuset (MoRo), and in the health study of the Sami population (9). This is the first time such extensive questions on drug use is applied in different study populations of same age in Norway, and these standardised questions make the comparability between the Norwegian health surveys easier, and facilitate the ability to combine results from several studies in the future.

In ideal situations, an independent "gold standard" is available when developing a questionnaire (23). For a drug exposure, a true gold standard would be a list of all drugs the study participant has taken, including dose, duration, and dates for exposure. This drug list might be a diary of prescriptions kept by the study participants or, perhaps more readily available, a computerised database of filled prescriptions. Norway has at the moment no prescription register based on either medical records or pharmacy records. However, the Norwegian Institute of Public Health is now establishing a national prescription register covering the entire nation based on prescriptions from Norwegian pharmacies (24). This register will offer unique possibilities for doing record-linkage studies within a pharmacoepidemiological perspective. Also, the register may be used to make validity studies of drug use questions in the Norwegian health surveys in the future.

\section{ACKNOWLEDGEMENT}

The data collection was conducted as part of the Oslo Health Study 2000-2001 and the Oppland/Hedmark Health Study 2000-2001 in collaboration with the National Health Screening Service of Norway - now the Norwegian Institute of Public Health. We are thankful to Dr. Torleiv Svendsen, Oppland Sentralsykehus, Lillehammer for letting us use the questions about antiepileptics from his epilepsy project in Oppland County. The authors thank Dr. Per G. Lund-Larsen for his enthusiasm in establishing a system for handling and ascertainment of the open-ended questions on trade names and reason for using the drugs.

\section{REFERANSER}

1. Furu K, Straume B, Thelle D. Legal drug use in a general population: association with gender, morbidity, health care utilization, and lifestyle characteristics. J Clin Epidemiol 1997; 50 (3): 341-349.

2. Laukkala T, Isometsa E, Hamalainen J, Heikkinen M, Lindeman S, Aro H. Antidepressant treatment of depression in the Finnish general population. Am J Psychiatry 2001; 158 (12): 2077-2079.

3. Olfson M, Marcus SC, Weissman MM, Jensen PS. National trends in the use of psychotropic medications by children. J Am Acad Child Adolesc Psychiatry 2002; 41 (5): 514-521.

4. Preville M, Hebert R, Boyer R, Bravo G. Correlates of psychotropic drug use in the elderly compared to adults aged 18-64: results from the Quebec Health Survey. Aging Ment Health 2001; 5 (3): 216-224.

5. Rosvold EO, Bjertness E. Illness behaviour among Norwegian physicians. Scand J Public Health $2002 ; 30$ (2): $125-132$.

6. Eggen AE. The Tromso Study: frequency and predicting factors of analgesic drug use in a free-living population (12-56 years). J Clin Epidemiol 1993; 46 (11): 1297-1304.

7. Eggen AE. The application of population based health surveys in pharmacoepidemiologic studies in Norway. Nor J Epidemiology 2001; 11 (1): 41-4.

8. Bjartveit K, Foss OP, Gjervig T, Lund-Larsen PG. The cardiovascular disease study in Norwegian counties. Background and organization. Acta Med Scand 1979; (suppl 634): 1-70.

9. Skurtveit S, Furu K, Rosvold EO, Straand J. Spørsmål om legemiddelbruk i de store befolkningsundersøkelsene - fra enkeltspørsmål til full oversikt. Nor J Epidemiology 2003; 13 (1): 137-146. 
10. Health interview surveys. Towards international harmonization of methods and instruments. de Bruin A, Picavet H, Nossikov A, editors. WHO Regional Publications, European Series, No. 58. Copenhagen: WHO Regional Office for Europe, 1996.

11. Gordis L. Assuring the quality of questionnaire data in epidemiologic research. Am J Epidemiol 1979; 109: 21-24.

12. West S, Strom B, Poole C. Validity of pharmacoepidemiology drug and diagnosis data. In: Strom B, editor. Pharmacoepidemiology, $3^{\text {rd }}$ edn. John Wiley \& Sons, 2000: 661-705.

13. Furu K, Thelle D. Validity of questions in the use of specific drug-groups in health surveys. Pharm World Sci 2001; 23 (2): 50-54.

14. Norwegian Institute of Public Health. http://wwwfhi.no/tema/helseundersokelse/oslo/. 11-4-2003.

15. WHO Collaborating Centre for Drug Statistics Methodology. Norwegian Institute of Public Health. http://wwwwhocc.no/atcddd/. 2003.

16. Lamberts H, Wood M, Hofmans-Okkes I. The international classification of primary care in the European community with a multi-language layer. Oxford: Oxford University Press, 1993.

17. Norwegian Institute of Public Health. http://www.fhi.no/tema/helseundersokelse/oppland_hedmark/. 1-72003.

18. Søgaard A, Selmer R, Bjertness E, Thelle D. The Oslo Health Study: The impact of self-selection in a large, population-based survey. Submitted.

19. SPSS Inc. http://www.spss.com/. 22-4-2003.

20. West SL, Savitz DA, Koch G, Strom BL, Guess HA, Hartzema A. Recall accuracy for prescription medications: self-report compared with database information. Am J Epidemiol 1995; 142 (10): 1103-1112.

21. Kehoe R, Wu SY, Leske MC, Chylack LT. Comparing self-reported and physician-reported medical history. Am J Epidemiol 1994; 139 (8): 813-818.

22. Neutel CI, Walop W. Comparing two different approaches to measuring drug use within the same survey. Chronic Dis Can 2000; 21 (4): 150-156.

23. Olsen J. Epidemiology deserves better questionnaires. IEA European Questionnaire Group. International Epidemiological Association. Int J Epidemiol 1998; 27 (6): 935.

24. Furu K. Drug utilisation in a public health perspective: Establishing a national prescription register in Norway. Nor J Epidemiology 2001; 11 (1): 55-60. 